\title{
FOOD SUPPLY CHAIN DURING PANDEMIC: CHANGES IN FOOD PRODUCTION, FOOD LOSS AND WASTE
}

\author{
SHAHLA M. WUNDERLICH \\ Nutrition Optima LLC Princeton New Jersey, United States of America
}

\begin{abstract}
The global COVID-19 pandemic of 2020 triggered disruption in almost all areas of the Food Supply Chain (FSC). During this year many confounding factors contributed to the disruption of the normal FSC and impacted the system adversely. This includes the agricultural food production system, the first phase of the FSC, to the final delivery of food to consumers. Food was lost or wasted as farmers were unable to transfer and distribute the food to retailers. Food shortages became problematic and consumers were not able to obtain necessary staples. Then consumers started to purchase too much (hoarding), as they feared shortages, which resulted in both rises in food prices and in higher food waste by consumers. Several reports indicated that food waste during this period was remarkably more than in pre-pandemic times. These situations were worsened as the pandemic continued. In this paper we define food loss as occurring mostly during the agricultural food production and food waste that mostly happening during distribution of food at the retailer and consumer levels. The food loss and waste (FLW) both have been shown to add to the diminution of the natural resources and the rise in greenhouse gas emissions. The high level of greenhouse gas in turn can harm the environment. In the United States (U.S.), similar to other countries, natural resources such as land (about 50\%) and water (67\%) are used for agriculture and food production. The main objective of this paper is therefore, to emphasize some of the current findings on the potential impact of the pandemic on the FSC which resulted in more FLW. Many reports suggest every stage of the FSC can be a significant contributor of FLW and environmental resource depletion. Long-term strategies must be implemented to keep the FSC robust, stable and sustainable during unfavorable circumstances and crises.
\end{abstract}

Keywords: Environment, pandemic, consumer, Food Supply Chain, food loss and waste, sustainability.

\section{INTRODUCTION}

According to the United Nations (UN) agencies, the COVID-19 pandemic is not only a health emergency, but it has also been threatening the food security of people globally. Since March 2020, UN agencies have worked within their own mandates to protect food systems and delivery of food to people in need. The current global pandemic (COVID-19) has disrupted food systems around the world [1]. The Food Supply Chain (FSC) from farm to table has been impacted negatively by this pandemic. Changes occurred such as farmers not being able to distribute and transfer the food to retailers. Consumers, therefore, experienced shortages of specific foods and many stockpiled foods as they were afraid that there will be broader food scarcities in the future. These alterations in consumers' behavior, including their purchasing and eating practices, led to negative impacts on individual and global health status. Food waste increased as consumers were not able to consume all the food they purchased and led to massive spoilage and waste. It is important to note that these changes in the FSC were significantly different than the challenges created by previous natural disasters such as drought, floods and fires. In the case of natural disasters, the production of food itself is often severely disrupted. In the current pandemic however, food was produced at the source, but it was unable to move completely and normally through the FSC without major loss. A sustainable food system, including both adequate food production and a low food loss that provides sufficient food for all but more importantly for the food insecure population, thus becomes critical. The pandemic caused about 49 million people to move to extreme poverty [1]-[3]. 
The global food loss and waste, even in the pre-pandemic era, is estimated annually to be about one-third or about 1.3 billion tons of total food produced [4], [5]. Furthermore, it is estimated that in 2050, when the global population is projected to reach about 9.8 billion from the current population of 7.8 billion, the additional people can be fed by reducing the FLW rate. The Food Loss and Waste (FLW) reduction becomes even more critical to assure enough food at the time of global crisis [3]. The Food and Agriculture Organization (FAO) of the United Nations (UN) reports that the food loss and waste (FLW) is a global concern, and all nations must be taking actions to lessen FLW [5]. Moreover, not only does reduction of FLW result in more food available for the population, it also safeguards the environment by not using too many natural resources. If FLW stays at the current level, both food availability and the environment will suffer in the future. The FAO estimated that global FLW is about $25-30 \%$ of the total available food. In addition, the FLW in different parts of the world and the type of food losses are wide-ranging [5]. For example, the manner of FLW in developed counties may be different from developing countries.

The FLW can happen in any stage of the Food Supply Chain (FSC). Understanding of the main sources of FLW and systematic approaches to reduce FLW globally will help to provide enough food for all under different conditions: normal or during crises. This means that all who are involved in making food policy and agricultural sectors must work together to attain a sustainable food supply. It is also important to take lessons from other successful approaches and strategies that resulted in achievable and constructive solutions. This may help to reduce food loss and waste and support the protection of the natural resources and attainment of the United Nations sustainable developments goals for the future [6].

\subsection{Food Supply Chain}

The Food Supply Chain (FSC) defines the sequence of food production and distribution from farms to users. Figure 1 displays a simple model of the FSC. These interrelated steps bring food from farm to table, i.e., to the final users. That means that all the participants in this process impact each other and the movement of food across the supply chain [7]-[9]. The future will be more promising if the food system becomes more sustainable by using new

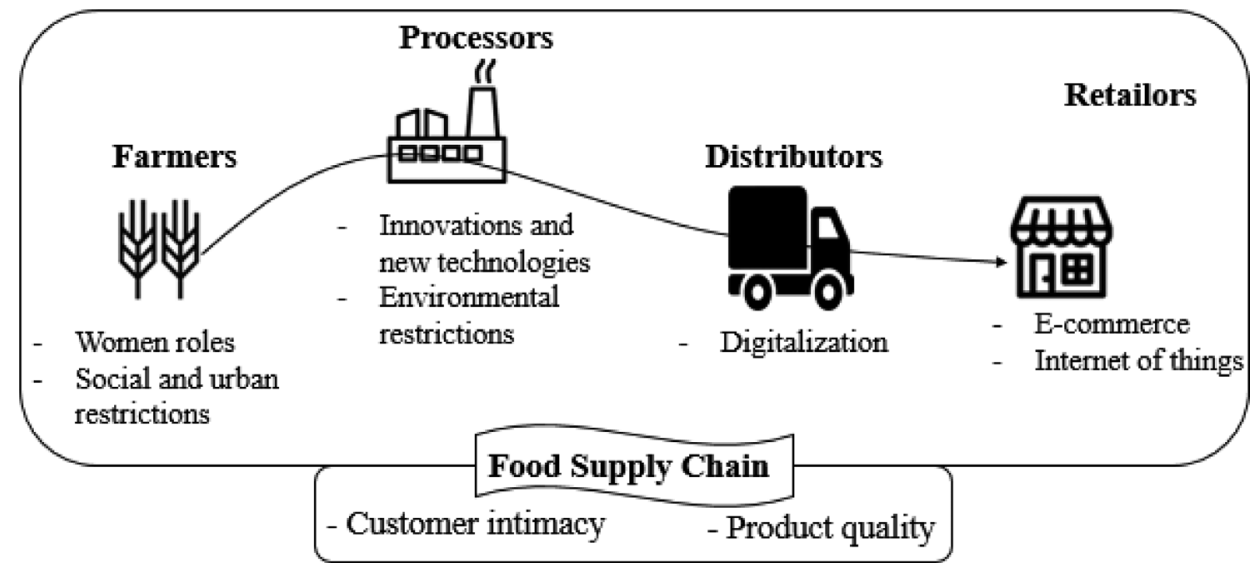

Figure 1: The business model innovation in the food supply chain. Nosratabadi, et al 2020 [9]. 
technology to achieve agricultural practices with higher crop yields and less food loss and waste (FLW) on all levels of the food chain.

Food production processes, unfortunately, can be disrupted by many factors such as the pandemic in 2020 and extreme climate impacts like unfavorable temperature, drought and other natural disasters. These disruptions can also occur at any stage of the FSC. Disruptions can occur not only at the food production phase but also in food processing industries, distribution, and in consumers' purchasing behaviors. For example, during the pandemic the enclosed food processing plants have been affected significantly by the mandate on social distancing, by shortages of personnel due to sickness, and by lockdown measures to prevent the range of the virus infection. In industries where the workers need to work in a closed and confined spaces, such as packing plants for fruits and vegetables or meat processing facilities, the mandate of social distancing, to ensure workers' safety and health, has brought lower efficiency of operations. Therefore, staff availability was reduced in many meat processing facilities. These disruptions in the FSC affected the meat packing plants in many countries including the US, Canada, Spain, Ireland, Brazil, and Australia [10]. The more automated industries, such as grain handling and processing, which depend less on laborers, have experienced less disruptions. Furthermore, the harvests were reduced in some parts of the world, and as a result many seasonal workers lost their jobs, which also restricted, and sometimes even stopped, the transport of food to markets. High-income countries that have advanced technological recourses faced less impact than low-income countries that are more labor dependent. Low-income countries need to develop supply chain contingency plans in order to overcome basic FSC logistic challenges [11]. As mentioned before, many meat processing plants, and food marketplaces were obligated to halt due to widespread COVID-19 infections among employees. Some dairy producers had no choice but to discard milk and other perishable crops as they could not transfer them to the distributers [10]. This resulted in breaks in the food supply chain. Both in developing and underdeveloped countries, where temporary or seasonal workers are used for agricultural food production, sorting, harvesting, processing, or transporting of crops to markets, the FSC was affected significantly. Therefore, consumers had a difficult time to obtain fresh vegetables and fruits, dairy, meat and fish in the initial phase of pandemic [1], [10], [12]. Consumers have also become inclined to compare the sustainable agriculture methods of food production as they became more aware of the issues of agricultural sustainability. Consumers were comparing the sustainability of conventional, organic and genetically manufactured food production in their food purchasing decisions [13-14]. There is a need to educate consumers not only about the sources and methods of food production but also about the sources of food loss and waste. Positive and constructive actions toward reducing FLW can make the world's food more available, sustainable and protect the health of the environment as well [13].

\section{FOOD LOSS AND WASTE}

The global production of food is measured in billions of pounds of food so that the world's population can be fed but unfortunately at the same time, much food is also lost and wasted. These agricultural activities use natural resources and consequently, wasting food depletes and can harm the environment. Wunderlich [14] describes how the environment can be protected by reducing Food Loss and Waste (FLW). Food that is left on the farm after harvest for a period of time, and not consumed, refers as food loss in this paper. Further spoilage and food loss also can happen during transport, handling and storage as well. Even in the distribution centers and in the supermarkets food that is not stored or handled properly will be 
lost. Food waste, on the other hand, mainly refers to the food that is not used and eaten and discarded at the consumer level either at home, restaurant or other places where people normally eat. These activities result in the loss of millions of pounds of edible food per year. At the same time there about 815 million people, largely in underdeveloped countries, who are in need of food and many are hungry and undernourished. It is estimated that in the United States alone, about 15.8 million households are food insecure [6]. It is estimated that with about a $15 \%$ reduction in food waste, all food insecure people in the U.S. could be fed. There are also estimated that if food losses could be lowered significantly globally, an additional 1 billion people could have adequate food security [7], [15]. The situation of FLW worsened during 2020 due to the pandemic and many farmers, for example in the U.S., allowed their products to spoil at the farm since it was more costly for them to transfer and distribute when the subsequent delivery phase such as retailers, restaurants, consumers were not accepting deliveries of food. The FSC was broken [15].

An overview recently published, by Hamid El Bilali at the University of Natural Resources and Life Sciences (BOKU), Austria describes some strategies to improve the FSC and to prevent food loss and waste [16]. In this overview the author mentioned that reduction of FLW is one of the approaches in the United Nations '2030 Agenda for Sustainable Development' which also includes the 'Sustainable Development Goals' (SDGs) in order to lessen the amount of food loss and waste. The author further presented some solutions to reduce FLW at all phases of the FSC from the pre-harvest/ production stage, and other phases of the food system including processing, packaging, transport, and delivery to the food retailers and ultimately reaching to consumers [16].

Moreover, Aldacoa, et al [17] published a paper describing the influence of the COVID 19 pandemic on the Spanish food supply chain (FSC) at each phase and this is illustrated in Figure 2.

Figure 2 illustrates how the COVID-19 pandemic triggered strong fluctuations and shortterm changes in consumer eating habits that influenced the FSC. The FLW also changed

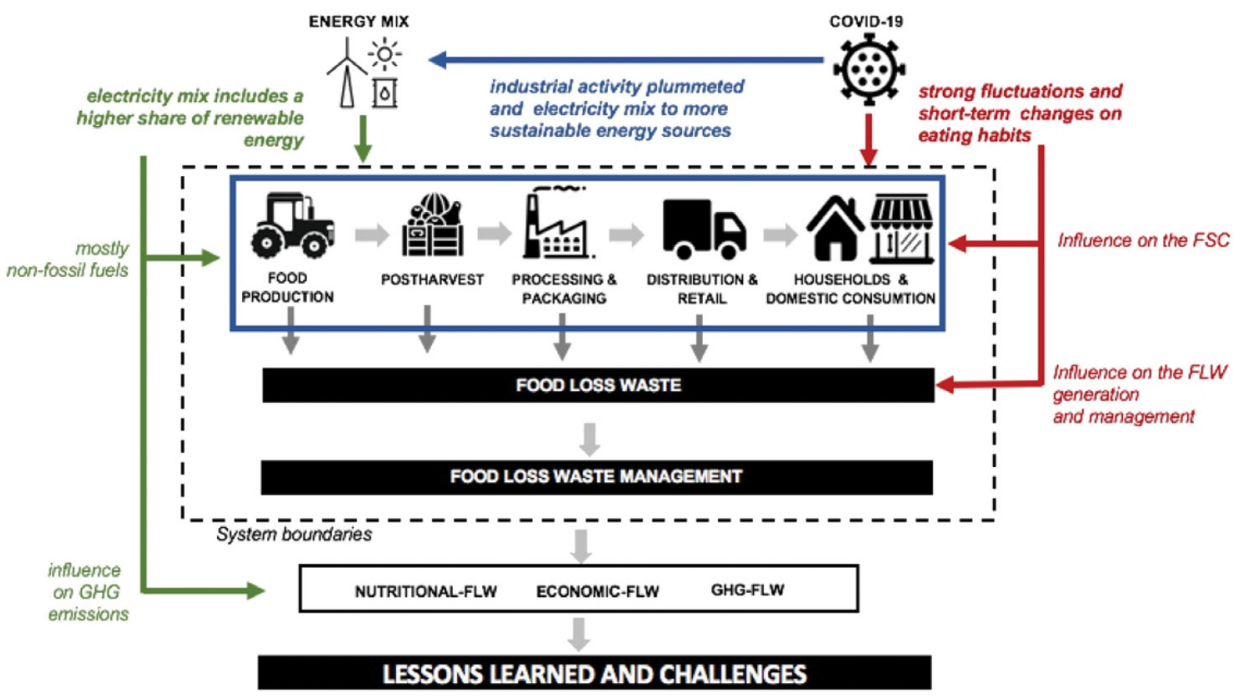

Figure 2: Overview of the Spanish food supply system influenced by the COVID-19 pandemic. Aldacao, et al 2020 [17]. 
as the Spanish government-imposed lockdowns and the food production and consumption changed significantly. The household FLW increased $12 \%$, the economic impact $(+11 \%)$, GHG emissions $(+10 \%)$, which all impacted FLW generation and management [17].

It is evident that the food supply chain must be improved in efficiency and resiliency so that disruption of food delivery during a pandemic or another emergency crisis can be minimized. At the same time, decreasing food loss and waste have been recognized as an important critical step to prevent food insecurity and reducing the negative impact on the planet earth's natural resources [17].

\subsection{Food Loss and Waste in Developing countries}

In 2018, the United Nations reports that in the underdeveloped countries, rate of the food insecurity is about $12.9 \%$ compared to the United States where the estimate is 15.8 million households that are food insecure (about 4.8\%) [5],[6].

The FLW in underdeveloped countries occurs primarily on the farm and some at the storage facilities. Often, food has been left on farms after the harvest and before being transported to the distributors which results in food spoilage. In addition, storage facilities are not optimal which affects in food damage. These countries have limited financial resources, education and technical support to build an optimal food system process. Therefore, in areas of the world such as Sub-Saharan Africa and Southeast Asia, the efforts should focus mostly on training particularly at the initial phases (harvesting and storage) of the FSC. It is also important to provide resources, financial support and education to combat the food loss as there is a great need for food supply for the people living in these areas of the world [6]. The food loss in these countries could be reduced if farmers are trained in proper harvesting, transporting and storage practices to safeguard the harvested food which in turn would reduce food damage.

Another factor that should be considered is the environmental protection and conservation of the earth's resources. The health of the environment is critical in securing availability of the natural resources such water and soil. If these measures are not taken, the capability of the world to produce good quality and quantity food for all will be impaired [13], [14].

\subsection{Food Loss and Waste in Developed Countries}

In the developed countries, the main problem is that a large amount of edible food is wasted by consumers at home and at establishments such as restaurants [18]. Recent movements are underway to try to reduce food waste, by encouraging people to accept foods that are not aesthetically perfect but nonetheless are edible and nutritious. Selling the not fine-looking (ugly) but still nutritious produce cheaper (about $40 \%$ lower) than perfect ones to consumers, and proper food labeling and portion control at restaurants are therefore becoming more popular in some countries such as the U.S and Japan [18]. A review of food loss and waste in both developing countries and developed countries was published by the author(s) previously that indicates that reducing FLW will help to conserve natural resources mainly at the initial phases of the FSC [7]. In the most recent paper published in the Journal of Science of Total Environment in 2020 during the early stages of pandemic, in Spain FLW was reported to be more than $12 \%$ higher than normal [17]. 


\section{IMPACT ON THE ENVIRONMENT}

The impact of FLW on the environment must be recognized and not ignored. As mentioned earlier, the agriculture sectors and consumers' behavior utilize natural resources and subsequently increase the rate of global climate change through green-house gas (GHG) emission. A report from the National Aeronautics and Space Administration (NASA) indicates that the earth's temperature has risen by almost $2^{\circ}$ Fahrenheit from 1880 to 2018 . This is mostly due to the large amount of carbon dioxide and other GHGs that have been released into the earth's atmosphere by industrial pollution and the usage of fossil fuel as well as FLW [19]. North America unfortunately is considered a major source of per capita food loss and food waste. The U.S. is the 2nd largest contributor in the world of GHG due to food production. This could be the equivalent of 37 million vehicles a year [20]. It is therefore evident that human lifestyles and behaviors must change to reduce FLW and with that the environment will be more protected and at the same time the rate of climate change globally will decrease.

\subsection{Management and Policies}

In order to manage and reduce FLW, governments and policy makers must be involved and establish practical strategies in all areas of food production and usage. For example, in the U.S. in 2013, the United States Department of Agriculture (USDA) and the Environmental Protection Agency (EPA) launched the US Food Waste Challenge [21]. This joint effort brought the topic of FLW to the public and set a national goal to cut food waste in half by 2030 . This goal aligns with targets set by the United Nations' Sustainable Development Goals [6]. The U.S Congress enhanced food donation tax incentives in 2015 and about 400 retailers and manufacturers, committed to reduce food waste by 2025 [7].

\section{MATERIALS AND METHODS}

This paper is primarily a review study of relevant published journal articles in English with majority of the publication dates between 2018-2020 and a few in the last 10 years. Main focus was on 2020 publications during the time of the COVID-19 pandemic. The databases used for this review were Science Direct, Sage Premier, US National Agriculture Library, Public Health Database and Google Scholar using keyword searches. The main objective is to learn about the scope of the food loss and waste issue globally and the impact of the 2020 pandemic on the food supply chain. Therefore, policy reports and efforts to lessen food loss and waste were explored. The reports and publications from governmental, international and private agencies and organizations, in addition to published journal articles were reviewed. Primary sources from the United Nations agencies and the Food and Agriculture Organization (FAO) as well as the United States Department of Agriculture (USDA), the US Environmental Protection Agency (EPA), the National Aeronautics and Space Administration (NASA) were used to retrieve the most current information. Also, reports by the research groups that are committed to global sustainability such as the World Resources Institute and the Natural Resource Defense Council also were reviewed. The online platforms, Google Scholar, and databases like Public Health were also considered [7].

Moreover, to explore the impact of COVID 19 on the food supply chain, the recent study conducted in Spain by Aldacoa, D. Hoehna, J. Lasoa, et al in 2020 and other pertinent published papers about the pandemic in 2020 [10]-[12] have been used to evaluate the FSC changes during the pandemic. The goal of the Spain study was to assess the economic, nutritional and environmental (i.e., climate change) consequences along the Spanish food supply 
chain in terms of FLW during the COVID-19 epidemic from the production to consumption of different typical Spanish foods [17]. The authors used two scenarios, pre- COVID-19 and during the outbreak. Pre-COVID was during the time that the state of emergency was not declared in Spain during 2019. This time period was used to baseline the food supply chain in Spain. The scenario during pandemic included from food production to household consumption, since consumption outside of the home was not allowed due to the lockdown. The pandemic scenario was recorded during weeks 11-15 (from March 9, 2020 to April 12, 2020) [17].

In another study by Vázquez-Rowe et al. [22] the Nutrient Rich Foods (NRF9.3) score was used as an indicator of the nutritional content of FLW. The economic FLW (E-FLW) index was also used to consider the economic value (profit or loss) of FLW caused for each food product and category. Both indicators, together with the Green House Gas emissions linked to FLW in food production and consumption (GHG-FLW) were established by the multivariable framework for potential decision-making [19].

\section{RESULTS AND CONCLUSIONS}

There are multiple stakeholders that influence sustainable food supply. Some efforts by stakeholders to keep the overall food supply chain normal and operational came to an abrupt halt when the pandemic occurred in the beginning of year 2020. Spain was a country hit hard by the pandemic and many routines and practices changed. A comprehensive study by Aldacoa, et al, which took a holistic approach and analyzed the consumer behavior changes that resulted in a more than $12 \%$ increase in the household FLW during in the initial phase of outbreak [17]. During this time adverse economic and environmental impacts occurred while nutritional quality was reduced. The study comparing pre and during COVID-19 during weeks 11-15 (from March 9, 2020 to April 12, 2020), showed that the food purchases increased by $29.8 \%$, in the first week of the emergency (Week 11 of 2020), compared to the pre-COVID time in 2019. The following week of the emergency, (Week 12), the food purchase increased by $10.9 \%$ compared to the baseline. This behavior may indicate that consumers initially purchased a large amount food and as a result there was no need to buy the same amount the following week (Week 12) and therefore the percentage was lower. In the subsequent week, (Week 13) food purchase was lower, and the reduction of food purchase was even more significant (20.3\%) [17]. These findings indicate that consumers' behaviors change greatly during the pandemic which impacted the food supply system significantly. This will be a warning for governments and policy makers to plan and respond accordingly. Also, in order to reduce FLW all stakeholders, including farmers, human resources, food industries, governments, policy makers and consumers must coordinate their efforts, behaviors, and practices to overcome these challenges. The pandemic also resulted in demanding human resource management. The working environment had to change in order to adopt new workplace policies and to reduce human contact [23]. It is valuable to learn and follow from successful initiatives and practices that are currently in place in some parts of the world. Having adequate food supply contingency plans is essential and crucial. Thus, as soon as a crisis is anticipated, such as a pandemic, they can respond appropriately to prevent another FSC breakdown.

The 2020 pandemic was and is a global concern. It has demonstrated that maintaining global food sustainability to feed the growing population and preserving the wellbeing of the environment is challenging unless coordinated efforts are devoted to market research and promotion of the concept that the FLW rate must be reduced so that it does not further 
impede food sustainability and further damage environmental resources. All participants in the food supply chain must work together in order to achieve positive and successful results [24]. Achieving the goal of attaining FLW reduction by $50 \%$ by 2030 will need this form of global partnership among governments and policy makers. Furthermore, establishing a more standardized labeling and correct date for food products which are easily understandable and reduce consumers' confusion about whether a product is safe to consume must be encouraged and promoted [25].

The 2020 pandemic brought more attention to the topic of FLW as it is not only affecting the food supply system, but it also depletes natural resources. The FAO issued a report in 2019 , stating that protection of the world ecosystem and its diversity is a priority in order to safeguard the agriculture and food supply system [26]. There are many sources of food loss and waste along the food supply chain. Actions by all stakeholders along the supply chain are needed to sustain a robust food supply system, which is resilient during emergencies, and at the same time preserves natural resources [7],[27]. Therefore, in order to achieve constructive outcomes, the assessment and examination of food loss and sources of food waste and possible actions must be explored. The evaluation should consider the facts that each region of the world requires different interventions as the geographical and agricultural practices vary due the regional conditions including weather and the availability of technological and other resources. Examples of potential methods to reduce food waste could be storing and salvaging and distributing to food banks [18]. These actions during a pandemic became vital in order to feed a large number of people in need of basic food supplies.

In developed nations, it has been shown that education to raise the knowledge of consumers about the food production methods and environmental impacts of each method has been effective. This approach has shown that consumers have improved the acceptability of cosmetically suboptimal foods. Some actions such as by Misfits (https://www.misfitsmarket. com) have been taken in the USA to sell cosmetically suboptimal produce at lower prices, thereby reducing food waste.

Nosratabadi, et al (2020) define changes during COVID-19 and challenges and lessons learned and the probable solutions to lessen some of the global food unavailability in the future [9]. They propose some solutions for refining the business model that vary based on the situation of a business in the FSC. The authors suggested that in order to close the gap between food supply and food demand for the next 50 years, is that all stakeholders in the FSC should optimize the value they are creating and delivering to their customers. The study also recommended approaches such as involving all investors in value creation processes and compatibility with the social and environmental factors as being critical in this method [9]. A report developed by the Economic Research Service (ERS) of the United States Department of Agriculture (USDA) in 2020 additionally describes that the "drivers of food loss on the farm and other pre-retail sectors, with a focus on economic incentives that underlie the way fresh foods are grown, processed, and marketed in the United States" [28]. The information in this report largely emphasizes foods such as fruits and vegetables which should be included in a healthy and balanced diet. Furthermore, another study indicates that the reduction of food loss and waste is not a responsibility of one nation, but it is a global obligation that requires actions by all nations in order to make enough food available for the world's population and safeguarding the earth's resources and economic security [29]. They proposed strategies to reduce FLW along the FSC and actions that have been taken in different countries to reduce FLW and to improve environmental health. Clearly, to be most effective in these actions, policy makers and regulators must be directly engaged in the process. FLW reduction policy must include protections against future crisis to safeguard food security and economic health. 
Nosratabadi, et al [9] also added the impact of the 2020 pandemic on the food supply chain at all levels of the chain. There are some recent published papers in this area that are mentioned in this review as well. The disruption on all stages of FSC during the initial months of COVID-19 was significant. As mentioned before, the major disruption came when farmers had difficulties to send their products to distributors, retailers and therefore there was shortages of food in local food shops and supermarkets. Consumers subsequently changed their shopping habits and purchased more food than they could eat, as they dreaded that there will be a sustained shortage of food in the future. They also preferred food takeaway and home delivery options as a result of social distancing recommendations and the closing of restaurants [30]. These practices ended up in creating substantial food loss and waste at several stages of the FSC. Later, the market stabilized again, and food unavailability was alleviated [9].

The Organization for Economic Co-operation and Development (OECD), representing 37 countries, met in June 2020 to analyze the impact of the COVID-19 pandemic on health and the economy and planned some strategies to prevent future crises. The organization also emphasized impacts on the environment, sustainability and preservation of natural resources and the linkage of environment and economic wellbeing "green recovery". Green recovery is resilient and sustainable and believed to be a win-win option to safeguard the environment and improve economic wellbeing. It is also considered to be the best relationship between COVID- 19 response and environmental health [31], [32].

\section{RECOMMENDATIONS}

The current pandemic has presented a challenging situation that shows how critical it is to be prepared and invest in a more inclusive, environmentally sustainable and resilient food supply system. This practice additionally needs to be continued after the crisis is over as well, so that the food system is well equipped in the face of global adversity and crisis including, and not only from a health pandemic, but also in the face of extreme climate change consequences. Long term policies should be in place to combat the future emergencies. The results are that the most recent estimates of overall food supply chain performance are highly variable from source to source which reflects the complexities involved with these estimates and as there are also ongoing research studies in this area that have not been published yet. This review attempts to shed some light on the food and environmental situation during the recent pandemic of 2020. Food producers and consumers were suddenly faced with an unprecedented global situation which took some time to be stabilized. This has been shown that the food supply chain can be vulnerable during a global crisis, either health or environmental. Therefore, a robust strategy must be implemented in order to secure the normal FSC which ensures food security, while reducing pressure on natural resources. Policies and management to reduce food loss and waste (FLW) have been identified as an effective approach to meet some of these objectives among other considerations.

The world has previously encountered numerous natural disasters, such as droughts, floods and fire among others which disturbed agriculture and food production in the past. However, the global pandemic of 2020 impacted the food supply in a different manner. Food was produced on the farm but could not reach the consumers due to lockdowns in many countries. Transport of food from farms was stopped because the movement of food by vehicles (trucks, for example) and air freight (planes were grounded) was reduced or paused. Lessons must be learned from these experiences to keep the FSC strong and resilient in order to withstand the future crises and keep the agriculture, food supply and economic security normal as much as possible. 
Many proposals and future goals have been submitted; some are mentioned in this paper. The importance of food sustainability and food security for all, and protection of the environment must become a higher global priority. More education and provision of resources are necessary in order to reduce food loss and waste and prevent another disruption of the food supply during global crises such as the pandemic of 2020. These goals can be accomplished only when all the participants in the food supply chain join forces to attain these objectives.

\section{ACKNOWLEDGEMENTS}

The author would like to thank and acknowledge the support of graduate students Natalie Martinez and Marielle Smoller in collecting and analyzing the initial data and reviewing the literature for the previous manuscripts cited in the reference list.

\section{REFERENCES}

[1] United Nations Policy Brief: The Impact of COVID-19 on Food Security and Nutrition, available at (https://www.un.org/sites/un2.un.org/files/sg_policy brief_on covid impact on food security.pdf, June 2020), (accessed 10 September 2020).

[2] United Nations System Standing Committee on Nutrition (UNSCN), The COVID-19 pandemic is disrupting people's food environments: a resource list on Food Systems and Nutrition responses, available at https://www.unscn.org/en/news-events/recentnews?idnews=2039 2020.

[3] Food and Agriculture Organization of the United Nations Report, The impact of COVID-19 on food security and nutrition, available at http://www.fao.org/policy-support/tools-and-publications/resources-details/es/c/1287907/2020, (accessed 19 August 2020).

[4] Food and Agriculture Organization of the United Nations, Global Initiative on Food Loss and Waste Reduction, Rome, FAO, (also available at http://www.fao.org/3/ai4068e.pdf), 2015.

[5] Food and Agriculture Organization of the United Nations Report, The state of Food and Agriculture, available at http://www.fao.org/state-of-food-agriculture/en/, 2019.

[6] United Nations, Sustainable Development Goals, available at https://www.un.org/sustainabledevelopment/hunger/, 2018.

[7] Wunderlich, S.M., \& Martinez, N.M., Conserving natural resources through food loss reduction: production and consumption stages of food supply chain. International Soil and Water Conservation Research, ISSN 2095-6339 2018, available at https://doi. org/10.1016/j.iswcr.2018.06.002 2019.

[8] Natural Resource Defense Council, Assessing corporate performance on waste reduction: a strategic guide for investors, available at https://www.nrdc.org/sites/default/ files/corporate-performance-food-waste-reduction-ib.pdf, 2017.

[9] Nosratabadi , S., Mosavi, A., \& Lakner Z., Food Supply Chain and Business Model Innovation, January 2020. DOI: n10.20944/preprints202001.0125.v1 USDA, Economic Research Service Bulletin No. (EIB-216) 39 pp. 2020.

[10] WIRED, Why Meatpacking Plants Have Become Covid-19 Hot Spots, available at https://www.wired.com/story/why-meatpacking-plants-have-become-covid-19-hotspots/, 2020 (accessed 31 December 2020).

[11] Food and Agriculture Organization, Policy responses to keep input markets flowing in times of COVID-19, available at http://www.fao.org/3/ca8979en/CA8979EN.pdf (accessed December 2020), DOI: 10.4060/ca8979en 2020. 
[12] Richards, T. J., \& Rickard, B., COVID-19 impact on fruit and vegetable markets. Canadian Journal of Agricultural Economy, 68, pp. 189-194. DOI: 10.1111/cjag.12231, 2020.

[13] Wunderlich, S.M., \& Smoller, M., Consumer awareness and knowledge about food sources and possible environmental impact. International Journal of Environmental Impact, 2(1), pp. 85-96, 2019. https://www.witpress.com/journals DOI:10.2495/EI-V2N1-85-96, 2019.

[14] Wunderlich, S.M., Protecting the Environment by Reducing Food Loss and waste Across the Food Supply Chain. WIT Transactions on Ecology and the Environment, 245, WIT Press, 2020, ISSN 1743-3541 (on-line), DOI:10.2495/EID200041. 31-39.

[15] Natural Resources Defense Council, https://www.nrdc.org/sites/default/files/wastedfood-IP.pdf, 2012.

[16] El Bilali, Hamid., Improving Supply Chains to Prevent Food Losses and Waste: An Overview. 1-19. (C) Burleigh Dodds Science Publishing Limited, 2020. http://dx.doi. org/10.19103/AS.2019.0053.08, 2020.

[17] Aldacoa, D. Hoehna, J. Lasoa, M. Margalloa, J., Ruiz-Salmóna, J., \& Cristobala, R., Kahhatb, P., Villanueva-Reyc,A., Balad, L., Batlle-Bayerd, P., Fullana-i-Palmerd, A., Irabiena, I., Vazquez-Rowe., Food Waste Management During the COVID-19 Outbreak: a Holistic Climate, Economic and Nutritional approach. Science of the Total Environment, 742, 2020, https://doi.org/10.1016/j.scitotenv.2020.140524.

[18] Sato, M., Nakano, M., \& Wunderlich, S., Effective utilization of the stockpiled food in the local government storage through food banks in Japan: reduction of food waste. WIT Transactions on Ecology and the Environment, 215, WIT Press, ISSN1743-3541. 2018.

[19] NASA Report. Global Temperature Anomalies from 1880 to 2018. https://svs.gsfc. nasa.gov/4626, 2019.

[20] Friedrich, T., Timmermann, A., Tigchelaar, M., Elison, Timm, O., \& Andrey Ganopolski, A., Nonlinear climate sensitivity and its implications for future greenhouse warming. Science Advances, 2(11), pp. e1501923, DOI: 10.1126/sciadv.1501923, 9 November 2016.

[21] USDA and EPA Launch U.S., Food Waste Challenge https://www.usda.gov/media/ press-releases/2013/06/04/usda-and-epa-launch-us-food-waste-challenge, 2013.

[22] Vázquez-Rowe, J., Laso, M., Margallo, I., García-Herrero, D., Hoehn, F.\& AmoSetién, A., Bala, R., Abajas, C., Sarabia, M.J., Durá, P., Fullana-i-Palmer, R., Aldaco., Food loss and waste metrics: a proposed nutritional cost footprint linking linear programming and life cycle assessment. International Journal Life Cycle Assess, (2019), DOI:10.1007/s11367-019-01655-1.

[23] Carnevale, J. B., \& Hatak, I., 'Employee adjustment and well-being in the era of COVID-19: Implications for human resource management'. Journal of Business Research, 116, pp. 183-187, DOI: 10.1016/j.jbusres.05.037, 2020.

[24] Pearson, D., \& Perera, A., Reducing Food Waste: a Practitioner Guide Identifying Requirements for an Integrated Social Marketing Communication Campaign. Social Marketing Quarterly, 2018. DOI: 10.1177/1524500417750830.

[25] Natural Resource Defense Council Report, The Dating Game: how Confusing Food Date Labels Lead to Food Waste in America, available at https://www.nrdc.org/sites/ default/files/dating-game-report.pdf, 2013.

[26] Food and Agriculture Organization of the United Nations Report (FAO), The biodiversity that is crucial for our food and agriculture is disappearing by the day, available at http://www.fao.org/news/story/en/item/1180463/icode/,2019 
[27] Wunderlich, S.M., \& Smoller, M., Food supply chain in the United States: Potential environmental impact. WIT Transactions on Ecology and the Environment, 215, WIT Press, ISSN 1743-3541, 2018.

[28] USDA, Economic Research Service Bulletin No. (EIB-216), 39 pp, 2020.

[29] Adamashvilia, N., Chiaraa,F., \& Fiore M., Food Loss and waste, a global responsibility? Economia agro-alimentare / Food Economy, 21(3), pp. 825-846, 2020. DOI: 10.3280/ECAG2019-003014, 2020.

[30] Shahidi, F. "Does COVID-19 affect food safety and security?", Journal of Food Bioactives, 9, pp. 1-3, DOI: 10.31665/JFB.2020.9212, 2020.

[31] OECD, "Food Supply Chains and COVID-19: impacts and Policy Lessons", 2 June 2020, http://www.oecd.org/coronavirus/en/, 2020.

[32] OECD (2020), "Focus on Green Recovery", https://www.oecd.org/coronavirus/en/ themes/green-recovery, 2020. 